\title{
INSTRUMENTALIZAÇÃO DE CAMPO: FUTEBOL, ESTRUTURA E PODER PÓS-64
}

\author{
Amanda Franco Grillo Zakir Jorge ${ }^{1}$ \\ Filipe Philipps de Castilho ${ }^{2}$
}

\begin{abstract}
Resumo
O trabalho investiga e analisa como, de 1964 até a redemocratização, o projeto político-econômico das instituições governamentais brasileiras instrumentalizou o futebol, por exemplo, por meio do inchaço do campeonato nacional e em obras de grandes estádios por todo o País, em vias de propaganda, exploração econômica e povoamento das regiões do Brasil, empregando o futebol como auxiliar ao plano de integralização nacional e demonstrando como a ditadura aproveitou-se do esporte para se consolidar e se manter.

Frisa-se que o estudo da instrumentalização política do esporte por parte do governo ditatorial brasileiro pós 1964 partiu da pesquisa estrutural de sua relação com o futebol, ambos como formas historicamente determinadas, envolvendo a investigação de aspectos políticos e também históricos, jurídicos, comunicacionais e econômicos, com o objetivo de se traçar o cenário institucional que possibilitou a exploração e instrumentalização do futebol pela ditadura como característica essencial dessa relação.

Como métodos, utilizou-se a análise qualitativa de literatura sobre o período, tanto em relação aos governos militares quanto sobre o futebol da época, além do exame de artigos de revistas e jornais sobre ambos; a hipótese confirmada foi a de que a ditadura explorou o lado econômico e propagandístico do futebol com visível sucesso, resultando posteriormente em um inchaço que viria a ser prejudicial tanto para a economia do país, quanto para o sucateamento de alguns aspectos do esporte, como estádios vazios e a falência de alguns times, acéfalos de torcida.

$\mathrm{O}$ entendimento dessas circunstâncias mostra-se relevante para o estudo dos aspectos referentes às relações das instituições governamentais atuais com o esporte e suas consequências políticas, jurídicas e econômicas a partir de um novo cenário institucional global, e para que sentido direcionam-se essas relações; as deliberações de tais questões serão o foco das vindouras hipóteses de pesquisa.
\end{abstract}

Palavras-Chave: Primeira ditadura; futebol; instituições.

\section{INTRODUÇÃO: O CONTEXTO POLÍTICO}

O regime ditatorial-militar no Brasil durou 25 anos, em um período que compreende 1964 até 1989, registrando nesse período de tempo a existência de seis governos, e pode ser dividido em cinco grandes fases, segundo Codato (2005): a primeira, a de constituição do regime político

\footnotetext{
1 Pós-graduanda UNINTER em Ciência Política: poder e establishment, amanda.franco.o@gmail.com, https://orcid.org/0000-0003-3653-2896.

${ }^{2}$ Graduando em Ciência Políca - UFPR, philipps_filipe@ @otmail.com, https://orcid.org/0000-0001-6266-0934.
} 
ditatorial-militar, correspondendo aos governos Castello Branco e Costa e Silva, que vai de março de 1964 até dezembro de 1968; a segunda fase, de consolidação do regime, correspondendo ao governo Médici, indo de 1969 até 1974; a terceira fase, de transformação do regime ditatorial, correspondendo ao governo Geisel, de 1974 até 1979, a quarta fase, de desagregação do regime, sob o governo Figueiredo, de 1979 até 1985; e a última fase, a de transição do regime ditatorial-militar para um regime liberal-democrático, abarcando o governo Sarney, de 1985 até 1989 (CODATO, 2005). Um período marcado por intensa repressão política, cassação e supressão de liberdades políticas e de ausência real de oposição, abarcando alguns aspectos de clientelismo e práticas de trocas de favores de cunho eleitoral (FERRAZ, 1999). Raymundo Faoro, ao analisar as articulações em torno da eleição presidencial de 1984, aponta uma série de manobras, continuísmos, acordos e disputas que viriam de longa data, e que mostrariam uma sedimentação de procedimentos e atitudes políticas que teriam eternizado um padrão de domínio oligárquico e estamental; para Faoro, a ordem estamental em vigência, ao longo da história do país, continuou a vigorar após 1964 e continuaria a existir após o fim do regime militar (REZENDE, 2011). O regime seria conduzido por "um estamento que, no centro do sistema de poder, agia em nome próprio. Assim, o estamento dirigente era formado pela 'estrutura militar e a estrutura capitalista vinculada ao Estado, representada pela tecnoburocracia' (FAORO, 1976). Dentro de toda essa amálgama de práticas burocráticas no período, teria grande papel o futebol e suas confederações de regência; uso, prática, propaganda e revolta dentro e fora de campo. O trabalho tem por objetivo investigar os usos e as relações entre o futebol e o poder pós-golpe de 1964, principalmente no que concerne aos regimes e governos de ideais anti-democráticos, que utilizaram o futebol como propaganda e veículo; por isso mesmo, também optou-se por uma investigação das relações entre o futebol e o governo de Jair Bolsonaro, presidente de extrema-direita com fortes relações de identificação com o regime militar. A justificava do trabalho reside no pouco material sobre o tema na literatura, principalmente acerca das relações mais contemporâneas do assunto.

$\mathrm{O}$ artigo começa com um tópico sobre os primórdios do futebol praticado no Brasil; em seguida, um tópico explanando acerca do futebol como ferramenta para o plano de integralização nacional durante o regime militar, tratando depois da chegada de Médici e do uso da Copa de 70 como propaganda política; depois é investigado mais a fundo os planos de integração nacional e o uso do futebol nesse contexto, passando depois pela construção de estádios faraônicos no período. Por fim, um tópico sobre as relações entre o governo de extrema-direita de Jair Bolsonaro e o futebol, seguido pelas considerações finais. 


\section{O FUTEBOL BRASILEIRO E AS INSTITUIÇÕES: PRIMÓRDIOS}

Praticado desde os fins do séc. XIX no Brasil, o futebol, primeiro praticado pela elite, depois incorporado pelas camadas mais pobres e proletárias, começa a tomar forma de fato na virada do século, tendo em meados de 1900 a fundação de diversos clubes ao redor do país, primeiramente centrados nas esferas das elites, e depois com a absorção, de maneira parcimoniosa das camadas mais populares (MÁXIMO,1999; FILHO, 1947). Tal absorção já encontraria elementos de interesses outros que não apenas os esportivos; historiadores como Joel Rufino, influenciados pela lógica marxista, viam nessa popularização do esporte uma forma de controle social (SANTOS, 2012). Seria alvissareiro para a burguesia da época a criação de uma "válvula de escape" para a cada vez mais crescente massa operária. As atividades futebolísticas nas fábricas, também fundamentais na difusão do esporte entre as camadas operárias, são alvo de controvérsias a respeito de seu caráter de controle das massas (SANTOS, 2012), pois longe de criar uma solidariedade entre empresas, patrões e empregados, o futebol serviria como elemento de identificação entre os trabalhadores de cada área (PEREIRA, 2000). Com o sincretismo e a institucionalização cada vez mais crescente, como a criação da entidade nacional para a regulamentação e centralização do futebol, a CBD, em 1916, o futebol brasileiro vai ganhando forma como prática, mas ainda incipiente em forma clara de disputa nacional, visto que os campeonatos de clubes ainda existiam apenas em caráter regional, os populares estaduais.

Os primeiros campeonatos de futebol que romperam as fronteiras regionais surgiram na década de 1950, sendo o principal deles a Taça Brasil, criada para indicar o representante brasileiro na Copa dos Campeões das Américas, atual Libertadores; o torneio contava apenas com os campeões do campeonato estadual de cada região, ou seja, não abarcando uma totalidade real do que era praticado em plano nacional. Em 1967, seria criado o Torneio Roberto Gomes Pedrosa agregando times oriundos de Rio de Janeiro, São Paulo, Rio Grande do Sul, Paraná e Minas Gerais, incorporando Bahia e Pernambuco no ano seguinte (SANTOS, 2012). Em artigo de outubro de 1970, a Revista Placar, publicação pioneira do jornalismo esportivo do país, publicaria uma matéria intitulada 'O Robertão é quase um Campeonato Nacional. O Campeonato Nacional é nossa grande solução', contando com os depoimentos de técnicos dos principais clubes brasileiros, dando ênfase à reclamação sobre a falta de viabilidade financeira e das viagens desordenadas dos clubes, 
incluindo uma discussão acerca da falta de abrangência do campeonato, com a escolha sem critério de alguns times participantes.

\section{O CAMPEONATO BRASILEIRO E O PLANO DE INTEGRALIZAÇÃO NACIONAL}

Segundo Codato (2005), o golpe de 1964 assinalou uma modificação decisiva na função política dos militares no Brasil, trazendo duas novidades: não se tratava mais de uma operação intermitente das Forças Armadas com um objetivo preciso, quase sempre o de combater a "desordem" (a política de massas) ou o "comunismo" (a política social) ou a "corrupção", mas sim de uma intervenção permanente. A garantia política que as Forças Armadas emprestaram aos governos civis, notadamente no pós-1930, convertia-se agora num governo militar (CODATO, 2005). Nota-se uma mudança de fato no regime político, em um movimento institucional das Forças Armadas. Foi o aparelho militar, e não um líder político militar, que passou a controlar primeiramente o governo, depois o Estado e, consequentemente, a cena política.

A Ditadura instaurada em 1964 seria saudada como uma "revolução democrática" por parte da sociedade civil, pois teria desde o começo a característica de manter um alto grau de institucionalização, com a permanência de partidos políticos e de eleições (CARVALHO, 2008). Para Bolívar Lamounier é fulcral compreender tais elementos de institucionalização para entender os rumos posteriores do regime, ao enfocar os antecedentes liberais dos militares que tomaram o poder e também da base de apoio composta pelos grupos civis de apoio ao golpe. (LAMOUNIER, 1988). O golpe de 1964, entretanto, para manter o projeto político de combate aos valores ditos de esquerda, se utilizaria de mecanismos repressivos e violentos, com a defesa dos valores da democracia e da civilização cristã, além da criação de um projeto de integralização nacional.

\section{O A CHEGADA DE MÉDICI}

Em 30 de outubro de 1969, Emílio Garrastazu Médici toma posse como vigésimo oitavo presidente do Brasil, em sessão conjunta do Congresso Nacional, obtendo 293 votos, prometendo restabelecer a democracia em sua gestão, o que obviamente não ocorreu. O governo Médici seria o ápice da centralização política. Em 1970 é lançado pelo governo a Loteria Esportiva, sob a égide da 
bonança financeira e de um ideal de otimismo financeiro, já como um sinal do chamado Milagre Econômico, tempos de crescimento acelerado da economia brasileira (SANTOS, 2012). Também data de 1970 a criação da já citada Revista Placar, que além da ênfase na análise do futebol em si, também ajudaria na divulgação da Loteria Esportiva, ao divulgar palpites e análises dos jogos envolvidos nas apostas, contando inclusive com um vínculo com a Caixa Econômica Federal (SANTOS, 2012). Seria no âmbito institucional do esporte, entretanto, a grande contribuição da revista, ao defender a criação de um campeonato nacional de clubes. Com uma redação de forte cunho político e uma defesa da moralização do esporte, a revista estamparia em sua edição de 14 de agosto de 1970 a matéria de capa "'A falência dos cartolas: como a CBD está matando os clubes", escancarando a forma de como os dirigentes das federações estaduais, principalmente de Rio e São Paulo, estariam cometendo desvios de repasses e de verbas dos clubes filiados, que muitas vezes lutariam contra a falência e contra problemas financeiros; a arrecadação vultuosa da CBD e das entidades não significaria necessariamente a bonança financeira dos clubes. A revista também mostrava a forma como os dirigentes visavam cargos políticos através das negociatas dentro das federações. Com base em tudo isso, além do âmbito esportivo, a revista fazia coro aos que defendiam um campeonato verdadeiramente nacional. Curiosamente, tal desejo seria partilhado pelo governo militar.

\section{A COPA DE 70 E A PROPAGANDA POLÍTICA}

Em 21 de junho de 1970, contra a Itália, o Brasil sagrava-se tricampeão mundial no Estádio Azteca, no México, em uma sonora goleada de 4x1. No Brasil de Médici e do 'Milagre Econômico", a conquista serviria como excelente instrumento de propaganda política, talvez o exemplo mais clássico e peremptório de como um regime pode se amalgamar com resultados esportivos com a intenção de propaganda política, comparável com o que fez a Itália nas conquistas de sua seleção nas Copas de 34 e 38, ambas sob a égide de Mussolini (CLEZAR, 2015) e a Argentina campeã da Copa de 78, Copa essa disputada na própria Argentina, e cuja comemoração do título seria concomitante ao período mais sangrento da ditadura de Videla, servindo também como propaganda ao regime militar em vigência no país (MAGALHÃES, 2019).

A Copa de 70 seria a primeira transmitida ao vivo pela TV, o que seria de vital importância na exploração massiva da imagem da seleção campeã, para muitos a maior da história; datam dessa 
época marchinhas cujas letras serviriam para glorificar o espírito do orgulho nacional, sendo a mais célebre a 'Pra Frente Brasil'”, composição feita por encomenda pelos patrocinadores da transmissão televisiva dos jogos da Copa no Brasil, por meio de um concurso para escolher o "hino da Copa". ${ }^{3}$ A canção voltaria à tona, por motivos políticos, em maio de 2020 , através da fala da entusiasta do governo Bolsonaro e então ministra da Cultura Regina Duarte, ao entoar a canção em entrevista em que minimizava as críticas aos elogios de Jair Bolsonaro à ditadura e seu desprezo pelos mortos e desaparecidos no período (MOURA, 2020).

Naquela tarde de 21 de junho de 1970, logo após o passe de Pelé para Carlos Alberto Torres estufar as redes do Estádio Azteca e selar a goleada e o título, Médici abriria os jardins do palácio da Alvorada e sairia a publico com uma bandeira na mão e uma bola no pé, enquanto adesivos eram distribuídos com a inscrição "Brasil, ame-o ou deixe-o" ruas a fora, transmutando futebol, governo, política, seleção e país em um mesmo amálgama carnavalesco (GASPARI, 2002).

$\mathrm{Na}$ volta ao Brasil, a primeira parada dos campeões mundiais seria o palácio do planalto, com a recepção dos jogadores pelo presidente Médici tornando-se um grande evento festivo. Uma multidão de aproximadamente 70 mil pessoas compareceria ao evento no planalto, cuja apresentação dos campeões se daria através de um esquema flexível de segurança, no ensejo de gerar uma suposta aproximação entre o povo, os jogadores e o "torcedor" Médici (CAETANO, 2015).

\section{A INTEGRAÇÃO NACIONAL}

O Governo Médici viria a reforçar um discurso já presente anteriormente no regime militar, preocupado com a integração das regiões do país. Durante sua gestão é possível observar uma série de políticas públicas que são criadas e utilizadas para realizar o projeto de "Integração Nacional" (SOARES, 2015). Tal projeto visava criar uma unidade real entre as regiões do Brasil, além de tentar dar ensejo ao crescimento de áreas mais remotas do país. A integração Nacional surge então como não apenas um programa, mas também como discurso do governo da ditadura entre os anos de 1969 e 1974 (SOARES, 2015). Os militares veriam no futebol um caminho de fomento para isso. O governo Médici enxergaria no futebol a chance para mostrar na prática o discurso empírico de integração, em um período que já contava com uma onda de expansão da fronteira agrícola e da

\footnotetext{
${ }^{3}$ https://oglobo.globo.com/cultura/saiba-como-pra-frente-brasil-virou-simbolo-da-ditadura-24417801
} 
construção da rodovia Transamazônica, por exemplo. Seria o ideal de "Brasil Grande"' (GASPARI, 2002). E o Campeonato Brasileiro servia para corroborar esse processo. O governo viabilizaria o torneio através do Ministério da Cultura, com ajuda financeira. O ministro da Educação e Cultura da época, Jarbas Passarinho, encontrar-se-ia com diversos jornalistas e dirigentes da época, visando abarcar e discutir questões acerca de uma remodelagem nos cursos do futebol no país. Com a intervenção do governo, o poder público passa a custear os traslados e estadias dos clubes, principal foco de discussão de dirigentes. A CBD, inclusive, chegaria a defender um campeonato financiado com dinheiro público (SANTOS, 2012). Importante notar o fortalecimento da CBD no período; Médici, presidente que mais se utilizaria do futebol como ferramenta política, e que em ocasiões 'civis' preferia falar de futebol em detrimento da política (GASPARI, 2012), tinha um interesse especial no esporte, enxergando um excelente veículo de propaganda; a CBD seria extensivamente defendida pelos três poderes, por ser uma entidade vista como deveras importante à máquina de propaganda e negociata do regime, instrumento pródigo para práticas clientelistas (CHAIM, 2014). Enfim, após tantos périplos, em 1971, finalmente começaria o primeiro campeonato brasileiro de futebol.

\section{O FUTEBOL E A INTEGRAÇÃO}

Entretanto, o primeiro Campeonato Brasileiro ainda traria poucas modificações, em um reflexo da hegemonia econômica da região sudeste, contando com quatro times do Nordeste, treze do Sudeste e três do Sul, sem a participação das regiões Centro - Oeste e Norte; tal fato reverbera até os dias de hoje, visto que a maioria dos clubes mais bem sucedidos do país são da região sudeste (CHAIM, 2014). De acordo com Soares (2012), 'desta forma, 65\% dos participantes do primeiro Campeonato Nacional estavam no eixo Rio de Janeiro - São Paulo - Minas Gerais. Tal disparidade regional - econômica ainda hoje é presente no campeonato, uma vez que entre os clubes participantes da Primeira Divisão, não há nenhum representante do Norte, um do Centro - Oeste (o Atlético Goianiense) e apenas dois do Nordeste (Sport, Náutico e Bahia)'’. Em 1971, no entanto, a insatisfação de diversas entidades regionais excluídas do processo começa a crescer, culminando na criação de campeonatos paralelos; tal descontentamento, inclusive, seria partilhado por lideranças políticas da ARENA, que enxergariam a falta de coesão e amplitude como contrárias ao ideal de "integração nacional”; na visão governista, algo inadmissível. Para a segunda edição do 
Campeonato Nacional seis clubes foram incluídos, com a inclusão da região Norte e com a presença de vagas para o Pará e Amazonas. A edição de 1973 seria ainda mais radical: o número de participantes aumentaria para quarenta, saltando para quarenta e dois em 1975. Todos os acréscimos substanciais seriam de times oriundos das regiões norte e nordeste, regiões estas que eram o foco do plano de integração nacional. João Paulo dos Reis Velloso, Ministro do Planejamento e Coordenação Geral, em Exposição inicial realizada em 1970 no Plenário da Câmara dos Deputados, diria que:

Desejo, desde logo, deixar claras as conclusões a que pretendo chegar, e que constituem definição de Govêrno do Presidente Médici, a saber: o Programa de Integração Nacional é, antes de tudo, a favor do Nordeste, do seu crescimento presente e da criação, na região, de um processo auto-sustentável de desenvolvimento; não haverá perda de recursos para o Nordeste, mas, antes, maior apoio do Govêrno Federal; não haverá perda de ritmo da industrialização; não haverá diminuição do programa do Banco do Nordeste; haverá intensificação dos dispêndios federais no Nordeste.

Tal cenário refletir-se-ia também em ajuda financeira, com o Banco Nacional do Nordeste oferecendo empréstimos para clubes do Norte e Nordeste montarem equipes competitivas para a disputa do campeonato nacional (CHAIM, 2014) além do incentivo de governo e CBD para a convergência de um projeto já em voga no período: as obras faraônicas; no caso do futebol, estádios faraônicos.

\section{A BONANÇA FINANCEIRA}

Não seriam apenas os times e as fórmulas de disputa os novos adendos da época; seguindo os passos das obras faraônicas do período, o futebol não ficaria de fora; o dito 'milagre econômico' caminhava a todo vapor, com os números do primeiro semestre de 1970 indicando um crescimento de $10,4 \%$, com o país iniciando a década como a décima economia do mundo, oitava do ocidente, primeira do hemisfério sul (GASPARI, 2012). O governo utilizaria o ideário de progresso associando-o ao maquinário político do regime, por meio de grandes obras ao redor do país, da usina atômica a ser montada em Angra dos Reis, a realização de grandes obras de novos e extensos metrôs em Rio e São Paulo, passando pelo grande nome do projeto da integração nacional, a construção da rodovia Transamazônica, com seus mais de quatro mil km ligando a Paraíba ao coração da Amazônia. O futebol não ficaria fora disso, no plano privado e no plano público. 
Durante a ditadura militar 52 estádios seriam construídos ou teriam sua capacidade de público aumentada consideravelmente; a década de 70, durante os governos Médici e Geisel, veria 32 dessas obras, sinal claro do uso do futebol para a máquina do regime. E não seriam apenas obras públicas: a ditadura também se embrenharia nos estádios privados, como por exemplo nos casos dos estádios do Morumbi e do Pacaembu, ambos em São Paulo; o Pacaembu, inaugurado em 1940, teria uma grande ampliação em 1970, assim como o Estádio do Morumbi, inaugurado em 1960 para os jogos do São Paulo Futebol Clube, e que também veria uma grande ampliação em 1970, graças a intervenção para obtenção de financiamentos e ajuda financeira do recém-empossado prefeito biônico Paulo Maluf, próximo ao presidente do SPFC à época, Laudo Natel (CHAIM, 2014). A reinauguração do Morumbi, inclusive, contaria com a presença de diversas autoridades do regime, como registra matéria da Folha de São Paulo de 25 de janeiro de 1970, ao registrar um almoço de Médici na casa do prefeito Paulo Maluf, seguido de ida ao Estádio do Morumbi para celebrar a reinauguração (1970: EM SP..., 2020).

Tal fato, vale registrar, não ficaria restrito somente ao contexto do regime militar; empréstimos e financiamentos com dinheiro público seriam reavivados com força quando da realização da Copa do Mundo de 2014 em solo brasileiro, ocasião em que o BNDES (Banco Nacional de Desenvolvimento Econômico Social) liberou R \$ 3,6 bilhões aos governos estaduais e municipais para a construção e reforma dos estádios que serviriam de sedes para jogos realizados pelo Brasil (RANGEL, 2009).

Outra ocasião marcada por empréstimos e financiamentos em períodos de repressão, mas desta vez em desacordo ao futebol, foi a experiência inglesa pós- Relatório Taylor, baseado em falsas evidências da polícia inglesa acerca da tragédia de Hillsborough, que vitimaria 96 torcedores do Liverpool Football Club, à época culpabilizados pelo incidente (JUSTIÇA..., 2016); o governo inglês disponibilizaria dinheiro público para as reformas dos estádios ingleses, visando a adequação dos mesmos para as novas regras de estrutura e modernização ( RUTHVEN, 2014).

\section{ESTÁDIOS: A TAÇA INDEPENDÊNCIA E OS ELEFANTES BRANCOS}

Em 1972 é organizada a Taça Independência, como parte dos festejos pela Independência do Brasil, festejos estes que contaram com grandes atividades cívicas pelo Brasil; a Taça 
Independência, organizada pela CBD e pelo governo brasileiro, seria o regime ainda utilizando a empolgação nacional pelo futebol causada pela conquista da Seleção na Copa de 70.

Para o evento seriam construídos diversos estádios em locais de pouca tradição esportiva, como Manaus, Maceió e Aracaju; além disso, afora o Macaranã no Rio de Janeiro (que no entanto ganharia iluminação nova) e do Mineirão em Minas Gerais, todos os estádios utilizados no torneio seriam de construção ou reforma deveras recente (CHAIM, 2014). Uma maneira de mostrar ao mundo a dita grandeza nacional.

O torneio, entretanto, encontrou um revés: mesmo com visitas e convites às confederações nacionais realizados de forma pessoal por João Havelange, presidente da CBD à época, muitas das seleções convidadas voltariam atrás, declinando da aceitação; Inglaterra, Alemanha, Itália e Espanha, selecionados de forte tradição, enviariam missivas cancelando a participação, diminuindo a qualidade técnica dos cotejos. Ironicamente, uma das seleções convidadas e que compareceriam seria o selecionado da União Soviética, país que por questões ideológicas se recusaria a jogar a repescagem da Copa de 74 contra o Chile, já sob a ditadura de Pinochet, um ano depois. Mesmo com os desfalques, a competição seria vendida como 'o maior torneio já realizado por um único país’ (CORDEIRO, 2015). O Brasil venceria a seleção de Portugal na final, realizada no Maracanã, com intensa reação de Médici, presente ao estádio, que segundo matéria da Folha de São Paulo:

(...) assistiu ao jogo visivelmente nervoso e várias vezes levantou os braços em sinal de decepção quando os jogadores perdiam um gol. Ele fumou durante o jogo 9 cigarros, que costuma ser sua média diária. Quando Jairzinho marcou o gol, o presidente jogou para o alto o rádio com que ele acompanhava o jogo, levantou-se com os dois braços para cima e laçou um entusiasmado grito de gol (NO GOL..., 1972).

Apesar do título na final, as deliberações da competição seriam a eleição de João Havelange para a presidência da Fifa em 1974 e estádios abandonados nas regiões sem grande tradição esportiva; fenômeno que seria visto mais uma vez após a Copa do Mundo de 2014, onde mais uma vez estádios nababescos seriam construídos em cidades sem a presença de times relevantes e de pouca torcida, ocasionando abandono e deteriorização (COPA..., 2018).

\section{ESTÁDIOS: QUANDO O CAMPO VIRA PRISÃO}

Entre 12 de setembro de 1973 até novembro do mesmo ano, o Estádio Nacional do Chile transformou-se em campo de concentração improvisado, direcionado aos inimigos políticos do 
regime de Augusto Pinochet, após o golpe de estado contra Salvador Allende no mesmo ano; no estádio, os mais de vinte mil presos eram constantemente torturados física e psicologicamente em todas as dependências do local, das arquibancadas ao campo; hoje, na parte superior de uma dessas arquibancadas pode-se ler a frase "Um povo sem memória é um país sem futuro" (CIFUENTES, 2015).

O Brasil também conheceu realidade semelhante, anos antes do caso chileno: após o golpe de 1964, durante as perseguições intensas aos que vistos como inimigos do novo regime, as prisões em massa faziam com que os presídios não tivessem espaço para todos aqueles que eram presos, e muitos locais alternativos foram utilizados, como o Estádio Caio Martins. Entre Abril e Julho de 1964 estimativas apontam que tenham passado pelo estádio mais de 1200 presos políticos, com fontes apontando 1800. Os presos dormiam nas bancadas do ginásio e, uma vez por dia, tinha permissão para ir ao relvado apanhar sol, sob vigilância armada nas bancadas (VAZA, 2018).

Curiosamente, os registros sobre o período se resguardam às memórias do cárcere: não existem documentos oficiais que apontem o Caio Martins como prisão. Uma reportagem da revista Trivela em 2009 procurou o comando do Exército Brasileiro, argüindo acerca do fato, e recebeu como resposta: “A Seção de Comunicação Social do Comando Militar do Leste informa que não há registros sobre o assunto em questão" (ZOBARAN, 2009).

\section{O CAMPO HOJE}

Em seus estudos sobre Walter Benjamin, Schlesener aponta que a ilusão de uma linearidade histórica indicando o futuro como sentido de um progresso, uma evolução em relação ao passado, seria um mito a velar a realidade, no sentido de que o "[...] mito esconde a essência sob uma aparência e subverte no imaginário as relações reais" (SCHLESENER, 2011, p. 55-56), e o enfrentamento da ideia de linearidade poria à vista a atualidade, em uma reestruturação metodológica que, rompendo com a sucessão entre passado e presente, os destacaria em sua simultaneidade (SCHLESENER, 2011, p. 59).

A partir de uma análise das formas sociais, Mascaro demonstra que a Constituição de 1988 manteve uma disposição institucional próxima e foi proveniente do ordenamento jurídico anterior, demonstrando a continuidade, no ordenamento jurídico atual, nas instituições políticas e no Estado hoje, de forma geral, do "arranjo institucional e social da ditadura militar" (MASCARO, 2018, p. 
79), indicando certa forma de constância política formal e institucional entre o regime militar e o presente que deve ser levada em conta na análise.

Com base nas concepções de Benjamin sobre a reversibilidade entre passado e presente, em sua interpretação do tempo irregular em que "[...] o passado se manifesta no presente em imagens dialéticas" (SCHLESENER, p. 89-90), apresenta-se aqui o elo entre a instrumentalização do futebol pelo governo militar pós 1964 e a mesma forma de instrumentalização pelo governo de Bolsonaro, eleito presidente da República em 2018, interpretada por meio da análise das formas institucionais do Estado que se mantém as mesmas, de modo que a instrumentalização do esporte por instituições políticas expressa-se ainda hoje, guardadas as peculiaridades de cada momento e as necessidades e objetivos de cada governo.

Pode-se exemplificar formalmente tal instrumentalização com as posturas adotadas pelo atual presidente Jair Bolsonaro em relação aos reflexos no futebol das medidas adotadas em combate ao coronavírus, desde afirmação de que a suspensão dos campeonatos estaduais seria causa de histeria (MAGALHÃES, SATIE, VENAGLIA, 2020), até mais recentemente a pressão para a retomada dos campeonatos, suspensos, afirmando que a sua retomada seria benéfica aos atletas (BOLSONARO DEFENDE..., 2020) ou que, caso ele tivesse o poder sobre tal decisão, permitiria sua retomada (PIRES, 2010). Dessa forma, estrutura um discurso político de que a paralisação dos campeonatos e, em última análise, de outras atividades políticas, econômicas e sociais, seria decorrente de uma decisão política motivada por interesses não necessariamente baseados em dados e fatos, mas sim econômicos e alheios às necessidades reais da população, decisão esta sobre a qual ele não teria controle e, se o tivesse, decidiria em sentido contrário, a favor do que julga serem os interesses e necessidades mais urgentes das pessoas.

Ainda que adotando ferramentas retóricas de argumentação no que seria transmitido como uma postura moderada e cautelosa ao afirmar que o desejado prosseguimento dos campeonatos somente ocorreria dentro das recomendações sanitárias, ou que teoricamente estaria disposto ao diálogo com as partes envolvidas, o uso dos meios de comunicação com o apelo a possíveis consequências econômicas ou sociais da paralisação do futebol nacional configura a exploração dos aparelhos ideológicos propriamente ditos, como instituições características que operam por meio da ideologia, entre os quais constariam o político e a mídia (ALTHUSSER, 1974, p. 46). Vinculando seu discurso em defesa da continuidade do futebol à continuidade de atividades econômicas em geral, e ao fato de que as medidas de restrição seriam mais prejudiciais do que sua flexibilização, mesmo que com cautela, a instrumentalização do futebol operada pelo governo Bolsonaro por meio 
do uso dos aparelhos ideológicos busca facilitar a exploração da agenda política de flexibilização das atividades econômicas em meio à pandemia, e não necessariamente tem como finalidade a atenção às reais necessidades da população, mesmo aquelas que possam estar vinculadas ao esporte, como o trabalho, o lazer, a identificação cultural e emocional, ou até mesmo questões sanitárias, entre outras.

Em relação a essa agenda, além da própria análise das formas e da ressignificação do método de análise do tempo, pode-se encontrar ligações entre os governos militares pós-golpe de 1964 e pós-democratização hoje a partir da percepção crítica sobre o poder, do exercício de tal poder, suas origens e os objetivos institucionais das decisões políticas, de forma a refletir na maneira como o futebol seria instrumentalizado por essas instituições como meio de operacionalização e propaganda.

A origem do poder, mais especificamente do poder como prerrogativa do soberano de decidir sobre o estado de exceção (SCHMITT, 1996, p.87) encontra seu princípio na decisão emanada pelo soberano, e não na norma jurídica (SCHMITT, 1996, p.90). O soberano decide sobre o estado de exceção, e no exercício desse poder, opta por suspender a ordem jurídica para a manutenção da ordem estatal e da soberania em si (SCHMITT, 1996, p.92). Mouffe (2019, p.2) afirma que, para Schmitt, a democracia como soberania popular se expressaria na identidade entre a lei e a vontade do povo, não sendo, assim, a democracia incompatível com um regime autoritário.

De fato, em consonância com a teoria de Schmitt, pode-se por exemplo observar com relevância nos atos normativos expedidos pelo governo militar durante a ditadura pós 1964 um apelo genérico à soberania popular e à defesa da ordem e do Estado como fundamentos das decisões. O Ato Institucional Número 1 (BRASIL, 1964) explicitamente atribui um caráter revolucionário ao golpe de 1964, fundamentando-o no interesse e na vontade nacional e por isso investido legitimamente do poder constituinte nas figuras dos chefes das forças armadas como representantes do povo, poder no qual posteriormente foi fundamentado o Ato Institucional Número 5 (BRASIL, 1968), que novamente evocando o mesmo objetivo de manutenção da ordem democrática antes atribuídos ao golpe de estado de 1964, conferiu ao presidente o poder de suspender as atividades do Poder Legislativo, os direitos políticos de quaisquer cidadãos e a garantia de habeas corpus nos casos de crimes políticos, além de, no Ato Institucional Número 6 (BRASIL, 1969), a partir da afirmação da plenitude e continuidade do poder constituinte conferido pelo golpe, alterar a composição e competência do Supremo Tribunal Federal. Em ambos os casos, 
destaca-se a vedação à apreciação judicial do mérito das decisões tomadas com fundamento nos atos institucionais.

Na mesma esteira ideológica de centralização do poder na figura do representante a partir de um fundamento que busca coincidir as decisões tomadas pelo presidente com um poder que teria origem na vontade popular, por isso seria democrático, verifica-se a assunção de posturas por parte de Jair Bolsonaro que, da mesma forma que afirmou a desnecessidade da suspensão dos campeonatos estaduais de futebol como medida de prevenção contra o coronavírus e que a suspensão seria causa de histeria e prejuízos à população, evoca também a vontade do povo e os valores democráticos como justificativa para a flexibilização das mesmas medidas, se fazendo presente em manifestações nas quais seus apoiadores, além desrespeitar as recomendações sanitárias formando aglomerações, rogam pela retomada das regulamentações autoritárias constantes nos atos institucionais do governo militar pós 1964 (SIMÕES, 2020).

Como amostra dos efeitos conjecturais das posturas adotadas pelo presidente, ressalta-se o efeito nas recentes manifestações civis em seu apoio, que chegam a contar com investigações relacionadas à possível formação de um grupo armado antidemocrático, inclusive com pedido judicial de desmobilização por parte do Ministério Público do Distrito Federal, pedido esse rejeitado pelo Judiciário com base na ausência de competência da esfera cível para o julgamento, sem negar a possibilidade de que o grupo esteja cometendo o crime. A própria representante desses manifestantes, a ex-candidata a deputada federal pelo DEM Sara Winter (pseudônimo de Sara Giromini) alega haver a presença de pessoas portando armas entre eles, mesmo afirmando que tais armamentos seriam para a proteção. Alega também que o grupo defende os valores democráticos e a soberania popular, estando prontos a morrer pela nação ('MILÍCIA ARMADA'..., 2020). Giromini teve sua prisão temporária autorizada por Alexandre de Moraes, ministro do Supremo Tribunal Federal, com base em investigação acerca da organização e captação de recursos para atos antidemocráticos, inclusive sendo o STF um dos alvos dessas manifestações (ENTENDA..., 2020; LIDERADO..., 2020). Ainda assim, a desmobilização dos manifestantes que se encontravam acampados na Esplanada dos Ministérios ocorreu apenas motivada pela ilegalidade de ocupação da área pública e descumprimento de decreto distrital que proíbe aglomerações durante a pandemia de coronavírus (MOTA, 2020).

$\mathrm{Na}$ mesma esteira das manifestações civis de apoio ao governo e ataque às instituições democráticas, pode-se observar o direcionamento comportamental em membros das próprias instituições consideradas mais próximas do presidente, como por exemplo, a do general Augusto 
Heleno, chefe do Gabinete de Segurança Institucional, ao afirmar publicamente, em documento denominado "Nota à Nação Brasileira", que eventual apreensão de telefone celular do presidente em investigação seria inaceitável e teria consequências imprevisíveis (GALVANI, 2020), manifestação que contou com carta de solidariedade redigida por militares mencionando, inclusive, a possibilidade de guerra civil como resultado das ações do STF (MILITARES..., 2020).

Nesse cenário institucional marcado por autoritarismo, instabilidades, falta de direcionamento coordenado e multiplicação de incertezas quanto à viabilidade política e sanitária da retomada do futebol nacional (VOLTA..., 2020), foi determinado que o Campeonato Carioca, por exemplo, retornasse dia 18 de junho em partida disputada no Maracanã, sem presença de torcedores, entre Flamengo e Bangu, disputa que terminou com a vitória do Flamengo por 3 a 0, enquanto no mesmo dia, no hospital de campanha do Maracanã, faleciam duas pessoas vítimas de coronavírus (EM MEIO..., 2020). Considerando que a pressão anteriormente feita pelo chefe o executivo, figura de autoridade cujo discurso possui alcance civil e institucional, em relação a retomada dos campeonatos e suas críticas às medidas sanitárias contra a propagação do vírus em meio à pandemia possam ter avolumado as instabilidades e redundado em uma tentativa de retomada precoce dos campeonatos, especificamente, no caso, o Carioca, vale ressaltar que essa não teria sido a primeira vez que a imagem do time vencedor da partida do dia 18 de junho de 2020, que conta com uma das torcidas mais numerosas do Brasil, é politicamente associada a de Jair Bolsonaro (PIRES, 2019). Em um sentido de instrumentalização do esporte com finalidades políticas, é observável a associação de figuras institucionais, direcionadas a determinado espectro ideológico e com objetivos políticos definidos, com times de destaque no futebol, de maneira semelhante à relação observada entre figuras relevantes dos governos militares de antes da redemocratização e a seleção brasileira.

Entretanto, a relevância política do futebol não se observa exclusivamente a partir da intrumentalização institucionalmente voltada para imposição de agendas política e economicamente contrárias aos interesses da população. Da mesma forma que, no Brasil, o futebol tem sido empregado como ferramenta institucional de direcionamento e suporte político-ideológico, seus elementos e atores também tem permeado ações e comportamentos que podem ser considerados como práticas que contrariam e se situam simbólica e pragmaticamente em oposição à sua instrumentalização, como por exemplo, mesmo que durante o governo militar há relatos do uso de estádios como prisões, hoje estádios abrigam em suas estruturas hospitais de campanha para o atendimento às vítimas de coronavírus (MONTEIRO, 2020), e da mesma forma que, em 
contraponto a pressão de alguns atores para a retomada precoce dos campeonatos, outros se manifestam publicamente de forma contrária, expressanto tanto o espanto pela retomada abruta em meio a pandemia e o receio pelo risco sanitário, quanto o desconforto pelas realizações dos jogos próximos a hospital de campanha enquanto o número de mortos pela doença continua alto (FLUMINENSE..., 2020; MONTENEGRO..., 2020; RÍMOLI, 2020).

Fenômeno semelhante pode ser observado em relação aos torcedores, com o crescimento do número de grupos e coletivos que interligam a identificação emocional com seus times de futebol ao autorreconhecimento como antifascistas (MAGRI, 2019), contando, em relação ao autoritarismo do governo de Jair Bolsonaro, inclusive com manifestações políticas moblizadas por torcidas organizadas em oposição ao atual cenário político (PIRES, 2020), sendo possível constatar que a instrumentalização institucional do esporte é contraposta por seus entusiastas em posturas politicamente ativas com alcance público e midiático, ainda que não sejam eles atores políticos institucionalmente vinculados.

\section{CONSIDERAÇÕES FINAIS}

A partir da análise das relações entre as forças políticas e seus representantes na ditadura militar e o futebol brasileiro, observa-se a instrumentalização, por parte do Estado, do apelo emocional e popular do esporte sobre a população como meio de construção ideológica favorável ao regime e suporte na viabilização de agendas econômicas e sociais direcionadas aos objetivos políticos do governo militar pós-1964. A instrumentalização institucional do futebol brasileiro como ferramenta política a partir do seu apelo social não se encerrou nos governos militares, sendo hoje observadas práticas que expressam essa mesma forma de invocação pelo governo do atual presidente Jair Bolsonaro, principalmente, mas não limitadas a enfraquecer, por meio do significado social do esporte, as medidas adotadas no combate à pandemia de coronavírus. Tanto em relação ao uso do esporte pelo Estado na ditadura militar, quanto ao uso do esporte hoje, são perceptíveis as agendas econômicas de fundo. Entretanto, a instrumentalização institucional do esporte encontra oposição política e social antiautoritária embasada nos mesmos apelos sociais nos quais o Estado se embasa, como por exemplo a que se observa vinda dos veículos da mídia e dos torcedores.

Assim, conclui-se também que o entendimento entre os paralelos formais, estruturais, temporais e legitimadores do exercício do poder entre os governos militares pós 1964 e o governo 
Bolsonaro hoje, contribui para a compreensão conjectural de como se desenvolve a instrumentalização política do futebol pelas instituições políticas específicas dos períodos, no sentido de que, ao retirar o foco do transcurso temporal propriamente dito e ressaltar as semelhanças entre os períodos que possam ter suas origens traçadas a partir das mesmas justificativas éticas, objetivos políticos e formais da produção e reprodução dos meios, torna-se possível a análise e a compreensão, a partir do mesmo método, de como o futebol também tem potencial de mobilização política como forma de resistência às práticas autoritárias, e não apenas como ferramenta inerte e limitado a ser explorado, por meio dos instrumentos de Estado, como uma forma de viabilizar agendas políticas instutucionalmente definidas e alheias aos reais interesses e necessidadas da população.

\section{REFERÊNCIAS}

1970: Em SP, Médici visita Câmara, praça Roosevelt e estádio do Morumbi, 26 de jan. de 2020. Folha de São Paulo. Disponível em: < https://www1.folha.uol.com.br/banco-dedados/2020/01/1970-em-sp-medici-visita-camara-praca-roosevelt-e-estadio-do-morumbi.shtml >; Acessado em: 11/04/2020.

ALTHUSSER, Louis. Ideologia e Aparelhos Ideológicos do Estado (notas para uma investigação). Lisboa: Editorial Presença/Martins Fontes, 1974.

BOLSONARO defende a volta do futebol: “A maioria aí ganha na faixa de 10 mil". Carta Capital, 7 de maio 2020. Disponível em: < https://www.cartacapital.com.br/politica/bolsonaro-defendevolta-do-futebol-a-maioria-ai-ganha-na-faixa-de-10-

mil/?fbclid=IwAR3g14kw32T5mfFXQa5T0g6VjBeihNpjTvWXQujqlvAamBHgh2XavCQ5ZCA >; Acessado em 13/05/2020.

BRASIL. Ato Institucional Número 1 de 09 de abril de 1964. Dissponível em: < http://www.planalto.gov.br//CCIVIL_03/AIT/ait-01-64.htm >; Acessado em 14/05/2020.

BRASIL. Ato Institucional Número 5, de 13 de dezembro de 1968. Disponìvel em: < http://www.planalto.gov.br//CCIVIL_03/AIT/ait-05-68.htm >; Acessado em 14/05/2020.

BRASIL. Ato Institucional Número 6, de $1^{\circ}$ de fevereiro de 1969. Disponível em: < http://www.planalto.gov.br//CCIVIL_03/AIT/ait-06-69.htm >; Acessado em 14/05/2020.

CAETANO, Everton Idalicio. O Futebol como propaganda política: Análise do discurso da revista VEJA na cobertura do mundial de 1970 no México. 2015. Trabalho de Conclusão de Curso. Universidade Federal de Santa Catarina, Florianópolis, 2015.

CHAIM, Aníbal Renan Martinot. A bola e o chumbo: futebol e política nos anos de chumbo da ditatura militar brasileira. São Paulo. Dissertação (Mestrado em Ciência Política) - Faculdade de Filosofia, Letras e Ciências Humanas, Universidade de São Paulo, 2014. 
CIFUENTES, Pedro. A memória do horror, no Estádio Nacional do Chile, 11 de jun. de 2015. El Pais. Disponível em: https://brasil.elpais.com/brasil/2015/06/11/deportes/1433979308_782555.html >; Acessado em: 14/03/2020.

CLEZAR, Mateus de Souza. Futebol e fascismo: como o fascismo italiano se manifestou no cálcio. Trabalho de Conclusão de Curso (Licenciatura em História), Universidade Federal do Rio Grande do Sul, Porto Alegre, 2015.

CODATO, Adriano Nervo. Uma história política da transição brasileira: da ditadura militar à democracia. Rev. Sociol. Polit., n. 25, p. 83-106, Nov. 2005.

COPA de 2014: 12 estádios, uma manada de elefantes brancos, 16 de jul. de 2018. Isto É. Disponível em: < https://istoe.com.br/copa-de-2014-12-estadios-uma-manada-de-elefantesbrancos/ >; Acessado em: 14/03/2020.

CORDEIRO, Janaína Martins. A ditadura em tempos de milagre: comemorações, orgulho e consentimento. 1. ed. Rio de Janeiro: Fundação Getúlio Vargas, 2015.

D’AVILA, Paulo M.. Assimetrias Políticas, Clientelismo E Democracia: Uma Discussão Conceitual. In: XXXI ENCONTRO ANUAL DA ANPOCS, 31, 2007, Caxambú. Seminário Temático. p. 2 - 18.

EM MEIO a pandemia, Carioca volta com jogo em Maracanã vazio, 19 de junho de 2020. UOL Notícias. Disponível em: < https://noticias.uol.com.br/ultimas-noticias/ansa/2020/06/19/em-meio-apandemia-carioca-volta-com-jogo-em-maracana-vazio.htm >; Acessado em: 24/06/2014.

ENTENDA inquérito do STF sobre manifestações antidemocráticas, 15 de junho de 2020. G1 Política. Disponível em: < https://g1.globo.com/politica/noticia/2020/06/15/entenda-inquerito-dostf-sobre-manifestacoes-antidemocraticas.ghtml >; Acessado em: 24/06/2020.

FAORO, Raymundo. 1976. “Romance sem heróis”. Veja, São Paulo, n. 399, 8 de abril, p. 3-6, 1976.

FERRAZ, Francisco César Alves. Influência militar na atual política brasileira: erosão ou retirada?. Rev. Sociol. Polit., Curitiba, n. 13, p. 179-182, Nov. 1999.

FILHO, Mario: O negro no foot-ball brasileiro. Rio de Janeiro,1947.

FLUMINENSE descarta jogar no Maracanã ao lado de hospital de campanha, 19 de junho de 2020. Terra. Disponível em: < https://www.terra.com.br/esportes/fluminense/fluminense-descarta-jogarno-maracana-ao-lado-de-hospital-decampanha,a1555ecf6345deda28807d1f01845d833322nl02.html >; Acessado em 25/06/2020.

GALVANI, Giovanna. General Heleno fala em "consequências imprevisíveis" caso celular de Bolsonaro seja apreendido, 22 de maio de 2020. Carta Capital. Disponível em: < https://www.cartacapital.com.br/politica/general-heleno-diz-em-consequencias-imprevisiveis-casocelular-de-bolsonaro-seja-apreendido/ >; Acessado em: 24/06/2020.

GASPARI, Elio. A Ditadura Escancarada. São Paulo: Companhia das Letras, 2002. 
JUSTIÇA inocenta vítimas em Hillsborough e aponta negligência policial, 26 de abr. de 2016. Uol Esporte. Disponível em: < https://www.uol.com.br/esporte/ultimas-noticias/afp/2016/04/26/mortede-96-torcedores-do-liverpool-em-1989-em-hillsborough-nao-foi-acidental.html >; Acessado em: 23/06/2020.

LAMOUNIER, Bolívar. O "Brasil autoritário" revisitado: o impacto das eleições sobre a abertura. In: STEPAN, Alfred. Democratizando o Brasil. Rio de Janeiro: Paz e Terra, 1988.

LIDERADO por alvo do STF, grupo faz ato com tochas e máscaras contra Moraes, 31 de maio de 2020. UOL. Disponível em: < https://noticias.uol.com.br/politica/ultimasnoticias/2020/05/31/grupo-300-protesto-supremo.htm > ; Acessado em: 24/06/2020.

MAGAlHAES, Lívia Gonçalves. A Copa do Mundo da ditadura ou da resistência? Comemorações e disputas de memórias sobre a Argentina de 1978. Estud. hist. (Rio J.), Rio de Janeiro , v. 32, n. 68, p. 675-694, Dez. 2019

MAGALHÃES, Leandro; SATIE, Anna; VENAGLIA, Gulherme. 'Gostaria que saíssem às ruas como eu', responde Bolsonaro a Maia e Alcolumbre. CNN, 15 de março 2015. Disponível em < https://www.cnnbrasil.com.br/politica/2020/03/16/gostaria-que-saissem-as-ruas-como-eu-respondebolsonaro-a-maia-e-alcolumbre >; Acessado em 13 de maio 2020.

MAGRI, Diogo. Torcidas antifascistas se multiplicam nas arquibancadas do futebol brasileiro, 25 de dezembro de 2019. El País. Disponível em: < https://brasil.elpais.com/esportes/2019-1225/torcidas-antifascistas-se-multiplicam-nas-arquibancadas-do-futebolbrasileiro.html?fbclid=IwAR2m4u8_Tbkx1rTD2AElzJzPy4LeFwgQHTQ3UrAMmCWyi1QJGryX LyXk5F8 >; Acessado em: 25/06/2020.

MASCARO, Alysson Leandro. Crise e Golpe. 1 ed. São Paulo: Boitempo, 2018.

MAXIMO, João. Memórias do futebol brasileiro. Estud. av., São Paulo, v. 13, n. 37, p. 179-188, Dec. 1999.

'MILÍCIA ARMADA': Justiça nega pedido do MP para proibir acampamento bolsonarista. BBC News Brasil, 14 de maio de 2020. Disponível em: < https://www.bbc.com/portuguese/brasil52656771 >; Acessado em: 14/05/2020.

MILITARES falam em "guerra civil", apoiam Heleno e atacam STF, 24 de maio de 2020. Carta Capital. Disponível em: < https://www.cartacapital.com.br/politica/militares-falam-em-guerra-civilapoiam-heleno-e-atacam-stf/?fbclid=IwAR0nmnweQ8-7uxb4J9YmCb5TgG7_kc0um1SE9blG1JZ1mcVIQRXVz1Hd9k >; Acessado em: 24/06/2020.

MONTENEGRO, do Botafogo, critica volta do Carioca: "Cada gol do Gabigol no Maracanã pode significar uma morte do lado", 17 de junho de 2020. SporTv. Disponível em: < https://globoesporte.globo.com/sportv/programas/troca-de-passes/noticia/montenegro-do-botafogocritica-volta-do-carioca-cada-gol-do-gabigol-no-maracana-pode-significar-uma-morte-dolado.ghtml > Acessado em: 25/06/2020. 
MONTEIRO, Danilo. Os estádios que viraram hospitais de campanha na luta contra o coronavírus, 27 de abril de 2020. Veja. Disponível em: < https://veja.abril.com.br/placar/confiraos-estadios-que-viraram-hospitais-de-campanha-contra-o-coronavirus/ >; Acessado em: 25/06/2020.

MOTA, Erick. Acampamento 300 do Brasil era ilegal, diz Secretaria de Segurança do DF. Congresso em Foco, 13 de junho de 2020. Disponível em: < https://congressoemfoco.uol.com.br/justica/acampamento-300-do-brasil-era-ilegal-diz-secretariade-seguranca-do-df/ >; Acessado em: 24/06/2020.

MOUFFE, Chantal. Pensando a democracia com, e contra, Carl Schmitt. Cadernos da Escola do Legislativo. $\quad$ v. $1, \quad$ n. 2, p. 87-108, 2019. Disponível em: < https://cadernosdolegislativo.almg.gov.br/ojs/index.php/cadernos-ele/article/view/353 >; Acessado em: 14/05/2020.

MOURA, Eduardo. Regina Duarte canta 'Pra Frente Brasil' e reclama de morbidez do coronavírus, 7 de maio de 2020. Folha de São Paulo. Disponível em: < https://www1.folha.uol.com.br/ilustrada/2020/05/regina-nao-quer-arrastar-cordeis-de-caixoes-e-dizque-covid-19-traz-morbidez-insuportavel.shtml. > Acessado em: 25/06/2020.

NO GOL de Jair, a Taça que fica, 10 de julh. de 1972. Folha de São Paulo. Disponível em: < https://acervo.folha.com.br//leitor.do?numero=4446\&anchor $=4357453 \& \mathrm{pd}=5 \mathrm{~d} 3 \mathrm{~b} 8 \mathrm{~b} 35 \mathrm{~b} 579407 \mathrm{eb0a}$ b51bd664da87d >; Acessado em: 15/04/2020.

PEREIRA, Leonardo Affonso de Miranda. Footbalmania -Uma História Social Do Futebol No Rio De Janeiro, 1902-1938. Coleção História do Brasi. Rio de Janeiro: Editora Nova Fronteira, 2000.

PIRES, Breiller. Bolsonaro usa o futebol para forçar relaxamento da quarentena, 29 de abril 2020. El País. Disponível em: < https://brasil.elpais.com/esportes/2020-04-29/bolsonaro-usa-ofutebol-para-forcar-relaxamento-daquarentena.html?fbclid=IwAR2MfBAO7yi6wEpejH_9qJ9GJdv55e_YT46379JQrlqA6FmOCm1s W26vAuM >; Acessado em: 13/05/2020.

Como o Flamengo se tornou instrumento da extrema direita, 18 de novembro de 2019. El País. Disponível em: < ttps://brasil.elpais.com/brasil/2019/11/13/deportes/1573670771_370418.html?fbclid=IwAR0_cLfD 5vHxTYYWiyfHQKIJkxm_EaGhBKvWYr2iFpXyh2fAjvJVoOVLgt0 >; Acessado em: 24/06/2020.

Torcidas antifascistas assumem linha de frente da mobilização contra Bolsonaro e atraem oposição, 1 de junho de 2020. El País. Disponível em: < http://brasil.elpais.com/esportes/2020-0601/torcidas-antifascistas-assumem-linha-de-frente-da-mobilizacao-contra-bolsonaro-e-atraemoposicao.html?fbclid=IwAR1rEx7ISIYNE0_6vUeBSP79ORaU2Rhqfqe9YLn4deez1EtsJx1DqRiaP xw >; Acessado em: 25/06/2020.

PLACAR. A falência dos cartolas, 14 de ago. de 1970. Disponível em: < https://books.google.com.br/books?id=YdIbPNcw6N0C\&hl=pt-

BR\&rview $=1 \& 1 \mathrm{r}=\&$ source $=\mathrm{gbs} \_$all_issues_r\&cad=1 >; Acessado em: 08/05/2020. 
RANGEL, Sérgio. BNDES abre crédito para estádios da Copa-2014, 17 de set. de 2009. Folha de São Paulo. Disponível em: < https://www1.folha.uol.com.br/fsp/esporte/fk1709200905.htm >; Acessado em: 20/05/2020.

REZENDE, Maria José de. A lógica autoritária do regime militar e os cálculos para controlar a democratização: a análise do jurista Raymundo Faoro sobre o processo político brasileiro. Rev. Bras. Ciênc. Polít., Brasília , n. 5, p. 167-192, Julho 2011.

RÍMOLI, Cosme. "É uma loucura. Estão alucinados", dirigente critica volta do futebol, 17 de junho de 2020. R7. Disponível em: < https://esportes.r7.com/prisma/cosme-rimoli/e-uma-loucuraestao-alucinados-dirigente-critica-volta-do-futebol-17062020 >; Acessado em: 25/06/2020.

RUTHVEN, Graham. Hillsborough Stadium Disaster 25 Years On: How English Football Changed Forever, 14 de abr. de 2014. Bleach Report. Disponível em: < https://bleacherreport.com/articles/2029350-hillsborough-stadium-disaster-25-years-on-howenglish-football-changed-forever >; Acesso em 15/04/2020.

SAIBA como 'Pra frente Brasil' virou símbolo da ditadura, 8 de maio de 2020. O Globo. Disponível em: < https://oglobo.globo.com/cultura/saiba-como-pra-frente-brasil-virou-simbolo-daditadura-24417801 >; Acessado em: 25/06/2020.

SANTOS, Daniel de Araujo dos. Futebol e política: a criação do Campeonato Nacional de Clubes de Futebol. Dissertação (Mestrado em História, Política e Bens Culturais) - FGV - Fundação Getúlio Vargas, Rio de Janeiro, 2012.

SCHELESENER, Anita Helena. Os tempos da história: leituras de Walter Benjamin. Brasília: Liber Livro, 2011.

SCHMITT, Carl. A crise da democracia parlamentar. São Paulo: Scritta, 1996.

SIMÕES, Eduardo. Bolsonaro defende democracia após discursar em ato pró-intervenção militar e diz que espera fim de quarentena nesta semana. Reuters, 20 de abril de 2020. Disponível em: < https://br.reuters.com/article/idBRKBN2221QB-OBRTP >; Acessado em: 13/05/2020.

SOARES, Filipe Menezes. O governo Médici e o Programa de Integração Nacional (Norte e Nordeste): discursos e políticas governamentais (1969-1974). Dissertação (Mestrado em História), UFPE, 2015.

VAZA, Marco. Caio Martins, o estádio-prisão da ditadura, 27 de out. de 2018. Público. Disponível em: < https://www.publico.pt/2018/10/27/desporto/noticia/caio-martins-estadioprisaoditadura-1849076 >; Acessado em: 19/03/2020.

VELlOSO, João Paulo dos Reis. A Estratégia de Desenvolvimento e o Programa de Integração Nacional. Brasília, 1970.

VOLTA do futebol: Guerra de liminares e briga política ainda travam RJ e SP, 10 de maio de 2020. UOL Esporte. Disponível em: < https://www.uol.com.br/esporte/futebol/ultimasnoticias/2020/06/10/volta-do-futebol-guerra-de-liminares-e-briga-politica-ainda-travam-rj-esp.htm >; Acessado em: 24/06/2020. 

Curitiba, 20 a 21 de agosto de 2020

ZOBARAN, Eduardo. Memórias do Cáercere. Trivela, fev. 2009. Disponível em: < https://issuu.com/f451midialtda/docs/trivela_36 >; Acessado em: 20/04/2020. 